\title{
POLÍTICA DE LÍNGUAS E HISTORICIDADE: NOTAS SOBRE UM (DES)ACORDO
}

Rejane Arce Vargas

Doutoranda (UFSM). Assistente de Pesquisa do Laboratório Corpus (PPGL-UFSM); Bolsista

RESUMO: Propomos aqui uma reflexão em torno da problemática desencadeada pelo Acordo Ortográfico que passou a vigorar em janeiro de 2009 no tocante a algumas implicações políticolinguísticas oriundas desse documento, levando em conta, especialmente, o modo como este passa a difundir um discurso sobre a língua, fundamentado no ideal de unificação (ortográfica). Para tanto, analisamos sequências discursivas do texto do Acordo, além de exemplares de discurso relativos à questão, veiculados na mídia. Essas sequências discursivas são submetidas a um olhar pautado na Análise de Discurso de orientação francesa e desenvolvida amplamente no Brasil por Orlandi, relativamente aos conceitos de historicidade e à tríade constituição-formulação-circulação (Orlandi, 2005). A análise do corpus nos encaminha para compreensão de que, a despeito da profusão de novos modos de circulação da linguagem, saberes legitimados sobre a língua sempre retornam, trazendo à cena cotidiana a contradição própria do político que constitui o real.

PALAVRAS-CHAVE: discurso, língua, político, circulação, historicidade.

\begin{abstract}
In this paper we propose a reflection about the problems arising from the Orthographic Agreement which started to be used since last January. We intend to reflect about some political and linguistic implications of the document especially the way it starts diffusing a discourse about language founded on the ideal of a(n) (orthographic) union. In order to do that we analyzed discursive sequences of the text of the Agreement as well as examples of discourses related to this topic spread by the media. These discursive sequences were submitted to investigation by Discourse Analysis which is widely developed in Brazil by Orlandi through concepts as historicity and the triad constitutionformulation-circulation (Orlandi, 2005). The analysis of the corpus led us to understand that despite the profusion of new ways of circulation of language, legitimated knowledges always revive bringing to day-by-day life the contradiction of the politic which constitutes the real.
\end{abstract}

KEYWORDS: discourse, language, politic, circulation, historicity.

\section{Introdução}

Desde janeiro de 2009, o Acordo Ortográfico da Língua Portuguesa passou a vigorar, notadamente, na mídia impressa e nos instrumentos didáticos destinados ao ensinoaprendizagem de Língua Portuguesa. Todavia, haverá ainda um tempo de adaptação até 2012, período em que as duas ortografias ('nova' e 'antiga') serão aceitas. Em face desse contexto, nossa reflexão se centra em problematizar o que se tem chamado de Novo Acordo Ortográfico (NAO). Interessa-nos especialmente complexificar o discurso de unificação linguística que vem se emoldurando em torno da questão. Tal fato pode ser pensado, por exemplo, por meio do exame do adjetivo 'novo' acrescido ao nome e o que esse acréscimo desencadeia em termos de efeitos de sentido.

Chamaremos aqui o Novo Acordo Ortográfico (NAO) simplesmente de Acordo Ortográfico (AO), pois essa perspectiva designativa abriga a posição teórica que adotamos em relação ao tema. Embora tenhamos como propósito problematizar a designação primeira (NAO), é a segunda (AO) que norteia este texto, pois compreendemos que um nome significa sempre política e historicamente, e sua entrada ou retorno nas discursividades não é casuística. Pensar um nome é pensá-lo enquanto memória e no jogo tenso de dizeres de outrora que retornam - os mesmos ou re-novados.

O AO é um projeto de unificação ortográfica da Língua Portuguesa (LP) aprovado em Lisboa, em 12 de Outubro de 1990, pela Academia das Ciências de Lisboa, Academia Brasileira de Letras e delegações de Angola, Cabo Verde, Guiné-Bissau, Moçambique e São Tomé e 
Príncipe, com a adesão da delegação de observadores da Galiza. Ele teria como finalidade "a defesa da unidade essencial da língua portuguesa", bem como para alavancar "o seu prestígio Internacional" (cf. AO) ${ }^{[1]}$.

O Acordo de 1990 deveria ter entrado em vigor em 1994, após a ratificação de todos os países que o formularam, o que não aconteceu. Hoje, e após dois Acordos Modificativos ${ }^{[2]}$, seus países signatários são Angola, Brasil, Cabo Verde, Guiné-Bissau, Moçambique, Portugal, São Tomé e Príncipe, e ele permanece aberto à adesão do Timor-Leste (cf. CPLP) ${ }^{[3]}$.

Do ponto de vista documental, serve de base para este estudo o Acordo Ortográfico, tal como este foi veiculado no Diário Oficial da União (DOU, Decreto nํㅜ 6.583, de 29 de setembro de $2008^{[4]}$ ) e ainda como este vem sendo interpretado em produções editoriais que o incorporaram. Essas materialidades serão tomadas em uma perspectiva discursiva, ou seja, entendidas como discursos sobre a língua, os quais demandam interpretações.

Desse modo, cabe apontar que a nomeação difundida como Novo Acordo Ortográfico remete a um documento datado do ano de 1990. Levando em conta esse fato, elaboramos uma breve cronologia que visa a abarcar de modo panorâmico a tramitação político-institucional do documento:

Quadro resumido da cronologia do Acordo Ortográfico de $1990^{[5]}$ :

\begin{tabular}{|c|c|}
\hline 1990 & $\begin{array}{l}\text { * Delegações de Angola, Brasil, Cabo Verde, Guiné-Bissau, Moçambique, Portugal e } \\
\text { São Tomé e Príncipe se reúnem na Academia das Ciências de Lisboa e elaboram o AO. } \\
\text { * Foram representantes do Brasil: Antônio Houaiss e Nélida Piñon. }\end{array}$ \\
\hline 1994 & $\begin{array}{l}\text { * É o ano de previsão da entrada em vigor do acordo, mediante ratificação dos países } \\
\text { que o elaboraram. } \\
\text { * Apenas Portugal (23/08/1991), Brasil (18/04/1995) e Cabo Verde ratificaram e a } \\
\text { vigência do AO não se efetiva. }\end{array}$ \\
\hline 1998 & $\begin{array}{l}\text { * Em } 17 \text { de julho, é assinado em Cabo Verde o Protocolo Modificativo ao Acordo } \\
\text { Ortográfico da Língua Portuguesa }{ }^{[6]} \text { que retira deste a data para entrada em vigor. } \\
\text { * Apenas Portugal, Brasil e Cabo Verde assinam o documento. }\end{array}$ \\
\hline 2004 & $\begin{array}{l}\text { * Em julho, os chefes de estado e de governo da } \underline{\mathrm{CPLP}^{[7]}} \text { aprovam, em } \underline{\text { São Tomé e }} \\
\text { Príncipe, um Segundo Protocolo Modificativo ao Acordo Ortográfico } \underline{\text { [8] }} \text {, o qual previa } \\
\text { a adesão do então emancipado Timor-Leste e ainda ratificações de apenas três países } \\
\text { da CPLP para a vigência do AO. } \\
\text { * Em outubro, o Brasil ratifica o Segundo Protocolo. }\end{array}$ \\
\hline 2005 & * Cabo Verde ratifica o Segundo Protocolo Modificativo ao Acordo Ortográfico. \\
\hline 2006 & $\begin{array}{l}\text { * E m } 17 \text { de novembro } \text { São Tomé e Príncipe ratifica o Acordo e os dois Protocolos } \\
\text { Modificativos. } \\
\text { * O AO não começa a vigorar mesmo com as } 03 \text { ratificações necessárias. }\end{array}$ \\
\hline 2008 & $\begin{array}{l}\text { * Em julho, o presidente de Portugal, Cavaco Silva, promulga a ratificação do } \\
\text { Segundo Protocolo. } \\
\text { * A partir de então, começam a ser instituídas, no Brasil e em Portugal, medidas } \\
\text { práticas, em termos editoriais, para a unificação ortográfica da LP. }\end{array}$ \\
\hline
\end{tabular}


Diante do cenário ilustrado pelo quadro acima, que abarca quase já 20 anos de tramitação do AO, alguns pontos alicerçam esta reflexão e dizem respeito, essencialmente, a indagações sobre:

$\varnothing$ o sentido propriamente político que emergiria da/na formulação Novo Acordo Ortográfico, nome que, nos últimos meses, vem figurando destacadamente em livros, dicionários, matérias jornalísticas, entre outros, bem mais do que, acreditamos, circulando em âmbito acadêmico-linguístico ou mesmo em uma instância deliberativo-participativa. Essa interrogação concerne à instância da formulação e circulação desse discurso sobre a língua;

$\varnothing$ ao que subjaz a ideia de unificação ortográfica, em termos de memória constitutiva dos saberes sobre as línguas, presentificada pela circulação do Novo Acordo Ortográfico, em especial no que o adjetivo 'novo' põe em funcionamento. Esse ponto vincula-se à constituição do discurso e soma-se à formulação e circulação deste, na medida em que nos interessa, sobretudo, a questão da produção de sentidos que movimentam o real da língua e, por essa via, o real da história que se processa no tempo presente.

Essas questões encontram aporte no pensamento de Orlandi (2005), ao postular que, na produção do discurso, há três momentos fundamentais a serem considerados: o de sua constituição, relativo à memória do dizer, em que intervém o contexto histórico-ideológico mais amplo; o de sua formulação em condições de produção e circunstâncias de enunciação específicas e o de sua circulação em certa conjuntura e segundo condições também específicas. São essas relações que visamos a estabelecer aqui, pontuando aspectos da historicidade no que concerne ao nome Acordo Ortográfico.

\section{O que é, para que serve?}

Problematização da questão: estrangeiros de nossa língua

Conforme a CPLP, a ratificação do AO objetiva "garantir a expansão da língua nos seus factores extra linguísticos, consolidando o discurso científico que produz, as expressões cultural e artística que cria, as relações económicas que veicula e as suas demais dimensões,

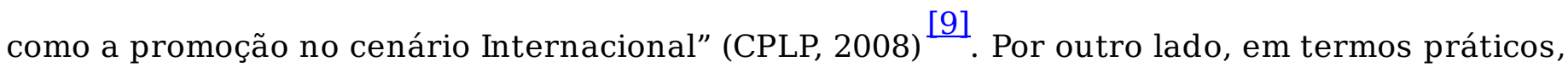
o AO acarreta uma mudança de $0,8 \%$ nos vocábulos da $\mathrm{LP}^{[10]}$, circunscrita basicamente à supressão da acentuação dos ditongos abertos 'ei' e 'oi'; do 'i' e 'u' tônicos, quando precedidos de ditongos nas palavras paroxítonas; eliminação do acento nos hiatos 'oo' e 'ee', assim como do trema e modificações no emprego do hífen. Todavia, essas mudanças que não colocam em jogo o sentido de formulações têm sido motivo de uma infinidade de produções editoriais: seja de dicionários, seja de livros didáticos, seja de reportagens nas quais são chamados a opinar os 'especialistas' (à moda de 'plantão tira-dúvidas') que não se cansam de enumerar as palavras que terão, a partir de então, uma nova grafia instituída.

No tocante ao que precede, podemos citar a matéria intitulada "Hora de remarcar os dicionários", publicada na Revista Língua Portuguesa (doravante RLP), edição de setembro de 2008, que ilustra o caráter problemático de algumas mudanças que já figuram nos então novos dicionários editados conforme o NAO. Já em agosto de 2008, por exemplo, eram lançados, na Bienal do Livro em São Paulo, três minidicionários, Houaiss, Aurélio e Michaelis. 
O linguista e gramático Evanildo Bechara declara, na matéria supracitada, ter receio de que Portugal decline de sua participação no $\mathrm{AO}$, como lembra ter ocorrido em outros momentos que envolveram tratativas dessa natureza, em 1931 e 1945.

Em 1931, foi aprovado o primeiro Acordo Ortográfico entre Brasil e Portugal, que visava a suprimir as diferenças, a unificar e simplificar a LP, mas que não foi posto em prática. Em 1945, quando o Acordo Ortográfico tornou-se lei em Portugal, não foi ratificado pelo governo brasileiro, de modo que continuou sendo praticada aqui a ortografia anterior, a do Formulário Ortográfico de 1943, instituído pela Academia das Ciências de Lisboa e aprovado pela Academia Brasileira de Letras, em 29 de janeiro de 1942, o qual previa, no item primeiro, a "inclusão de brasileirismos consagrados pelo uso" e, no segundo, a "inclusão de estrangeirismos e neologismos de uso corrente no Brasil e necessários à língua literária". Mas, em contraponto, em terceiro lugar figurava a "substituição de certas formas usadas em Portugal pelas correspondentes formas usadas no Brasil, consoante a pronúncia e a

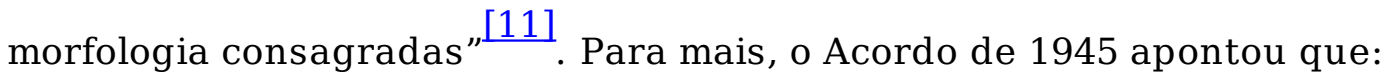

\begin{abstract}
A entrada em vigor, no nosso País, da reforma ortográfica de 1911, que o Brasil não adoptou, trouxe como consequência diferenciações sensíveis no regime da escrita, com prejuízo da unidade intercontinental da língua portuguesa. A fim de obviar aos inconvenientes da situação criada, a Academia das Ciências de Lisboa e a Academia Brasileira de Letras tomaram a iniciativa de um acordo ortográfico tendente a restabelecer, mediante transigências mútuas, a unidade dos dois sistemas (Acordo Ortográfico, Decreto N. 35 228, de 8 de Dezembro de $1945)^{[12]}$.
\end{abstract}

Como observamos, por meio dos recortes acima, há bastante tempo, acordos e/ou reformas apresentam um caráter tenso, seja do ponto de vista diplomático entre países, seja do ponto de vista prático, no que tange à efetividade de mudanças nas línguas.

\title{
2. (Des)Ligados por hífen
}

Sobre as divisões do político

Atualmente, no que tange à ampla divulgação do NAO, o hífen, que constitui três (XV, XVI e XVII) das vinte e uma bases do AO, parece ser o traço da contenda, operando antes uma disjunção do que a união de elementos linguísticos. Todavia, na RLP, temos uma mostra das controvérsias sobre o hífen, seguramente no que diz respeito ao mercado editorial recente: na matéria (op. cit.), Paulo Geiger, da Lexikon Editora, aponta para a inconsistência dos critérios, considerada a forma como estes vêm sendo apresentados nas publicações que já levam em conta o NAO. Geiger conta que, ao enviar a Houaiss uma lista de palavras a respeito das quais questionava sobre os critérios de hifenização, esta lhe retornara com anotações, mas os critérios não seriam claros: 'marca-passo' (verbo + subst), mas: limpa-trilhos e pegaladrão; bate-estaca e catavento; ruge-ruge e lerolero e por aí adiante. A matéria da RLP traz um outro exemplo: dicionário da Texto Editores (Portugal) registra: preeminência, preestabelecer e préescola. Aqui o critério seria o da tonicidade, mas quando se fala em português brasileiro e português europeu, seria possível uma distinção mediante esse critério? Já temos muitos exemplos que demonstram o contrário, e mesmo essas publicações parecem não considerar a heterogeneidade dos falares constitutivos da Língua Portuguesa (várias) e esta constituída/atravessada por outras línguas (de imigração, indígenas, africanas), quando apontam o prefixo 're', seguido de hífen com palavra iniciada por 'e', como átono (como em reedição, re-educação, re-eleição). 
Essas questões nos encaminham a uma reflexão relativa ao conceito de espaço de enunciação, tal como este é desenvolvido por Guimarães $(2003,2005,2007)$, pois, nos exemplos supracitados, o espaço de enunciação do Brasil que se está considerando é de caráter linear e homogêneo, tanto do ponto de vista espacial quanto simbólico. Todavia, esse espaço é multilíngue, onde várias línguas são praticadas, e o Português, ele mesmo, divide-se em vários.

De acordo com Guimarães (2003), no espaço multilíngue brasileiro, são praticadas em torno de 200 línguas. Nele (Ibid., 2005a), “funcionam o português, língua oficial e nacional e língua materna da grande maioria dos brasileiros, línguas indígenas, línguas de imigração, línguas de fronteira, e, mesmo precariamente, línguas africanas”.

Em face do que precede, vamos destacar algumas das especificidades do NAO, interessanos, particularmente, uma delas, que pode ser ilustrada pela redação do AO, em que, nas mais de 20 páginas prescritivas, podemos ler, por exemplo, a alternância ou oposição das grafias de:

$$
\begin{aligned}
& \text { antropónimos/antropônimos } \\
& \text { topónimos/topônimos } \\
& \text { tónica/tônica }
\end{aligned}
$$

Tal duplicidade diz respeito ao seguinte:

\begin{abstract}
3ํ) Levam acento agudo ou acento circunflexo as palavras proparoxítonas, reais ou aparentes, cujas vogais tónicas/tônicas grafadas $e$ ou $o$ estão em final de sílaba e são seguidas das consoantes nasais grafadas $m$ ou $n$, conforme o seu timbre é, respectivamente, aberto ou fechado nas pronúncias cultas da língua: académico/acadêmico, anatómico/anatômico, cénico/cênico, cómodo/cômodo, fenómeno/fenômeno, género/gênero, topónimo/topônimo; Amazónia/Amazônia, António/Antônio, blasfémia/blasfêmia, fémea/fêmea, gémeo/gêmeo, génio/gênio, ténue/tênue (AO,
\end{abstract} BASE XI - DA ACENTUAÇÃO GRÁFICA DAS PALAVRAS PROPAROXÍTONAS, p. 14) ${ }^{[13]}$.

A questão da tonicidade e timbre apontada de modo opositivo/alternado entre Português de Portugal/Português brasileiro ilustra sobremaneira o caráter político que objetivamos problematizar aqui e que concerne às línguas de modo geral, ao que se entende por língua, sobretudo. Sabemos que a tonicidade, o ritmo, a sonoridade das línguas implicam em modos de subjetivação. Vale sublinhar que o caráter político das línguas vincula-se ao que lhes é constitutivo e, portanto, excede e não se com-funde com política de línguas no sentido estrito.

O NAO vigora desde janeiro de 2009 e teremos quatro anos para nos adaptar às mudanças, período em que terão validade as grafias 'antiga' e a prevista nas bases do AO. Contudo, os livros didáticos, distribuídos gratuitamente pelo Ministério da Educação (MEC) às escolas públicas, devem seguir o NAO a partir de 2010, medida esta publicada no Diário Oficial da União (DOU), logo após a ratificação do AO por Portugal, em caráter de 'aviso' assinado pelo Presidente do Fundo Nacional de Desenvolvimento da Educação (FNDE) $\stackrel{[14]}{\text { : }}$
AV I S O S
As obras referidas no item 5.3.3 do Edital de convocação para inscrição no processo de avaliação e seleção de obras didáticas para o Programa Nacional do Livro Didático - PNLD 2010 - publicado no Diário Oficial da União de 14/01/2008, devem ser apresentadas em conformidade com as novas regras ortográficas do Acordo Ortográfico da Língua Portuguesa, assinado em Lisboa, em 16 de dezembro de 1990, e aprovado pelo Decreto Legislativo no 54, de 18 de abril de 1995, publicado no Diário Oficial da União, Seção 1, Página 5585, de 20/04/1995, e no Diário do Congresso Nacional, Seção 2, Página 5837, de 21/04/1995 (DOU, n. 46, 07/03/2008, p. 31) 15].

Diante do instituído acima, observa-se o caráter mercadológico instituído sobre o qual se assenta o NAO. A esse respeito, o gramático e linguista Evanildo Bechara entende que: 
Do ponto de vista político, a unificação ortográfica é importante. Implica numa maior difusão da língua portuguesa nos seus textos escritos. Mas a reforma poderia ter avançado mais e de forma mais inteligente na racionalização dos acentos e do hífen. As regras ainda são pouco acessíveis para o homem comum (BECHARA, 2008, em declaração sobre o AO) ${ }^{[16]}$.

O sentido político apontado por Bechara não diz respeito 'ao homem comum'. Notadamente, o político se desenvolve em uma esfera governamental, relativa à política linguística em um sentido que não se coaduna ao que pontuamos aqui.

Na distinção 'tradicional' entre as noções/conceitos de política e político, conforme sublinha Corten (1999), a política recebe caráter funcional de área especializada, enquanto que o político, mesmo que se considere sua configuração didático-teórica, permanece em uma instância de indefinição, que é diametralmente aumentada ao se falar em representação do político. Por essa razão, optamos em observar o funcionamento do político em circulação nos discursos que entretecem práticas de produção de linguagem/sentido, mediante a compreensão de que a noção de político, tal como concebida por Guimarães (2005), aponta para a contradição própria da constituição da linguagem, e seu caráter normativo não vem senão a estabelecer desigualmente uma divisão do real que afeta sempre os sujeitos (inclui os que não estão incluídos, do ponto de vista legal, normativo). Destaca-se, assim, a divisão dos sentidos, dos sujeitos em posições que delimitam o dizer e forjam modos de ser, estar, significar no mundo.

Por seu lado, Orlandi (2007) opera uma distinção: ela propõe uma reflexão em torno de política de línguas que prevê a descolonização linguística e a descolonização do linguista ${ }^{[17]}$, o que impõe pensar política linguística enquanto política de línguaS, assinalando o caráter político que aí se coloca, sem que de antemão se pressuponham teorias e a língua enquanto tal. O político, assim, está ligado ao funcionamento do real nas línguas, inscrito na diferença, no litígio por sentidos e não necessariamente a uma 'política' (lei, decreto etc.). Podemos pensar essa relação a partir de algumas sequências discursivas (SDs):

SD 1

Inovações da Classe C

"A gente" humilde

Pesquisas mostraram que a classe média baixa é a grande inovadora do nosso português. Aos poucos, expressões como "a gente" e "chama ela" vão ganhando prestígio social e devem virar norma. Esse movimento só tende a crescer com a expansão da classe C (SUPER INTERESSANTE, dez. 2008, p. 89) $\stackrel{[18]}{\text {. }}$.

\section{SD 2}

Transcrição de parte do telejornal SBT BRASIL: Nossa "nova" língua portuguesa, disponibilizada no You Tube

(Apresentadora/Cynthia Benini) Brasileiros vão ter de reaprender a escrever. Novas regras de ortografia começarão a valer no ano que vem.

(Apresentador/Carlos Nascimento) Há muito tempo, os países de língua portuguesa tentam aí entrar num acordo e unificar a ortografia. Será que dessa vez vai?

(Comentarista/Joseval Peixoto) Somos separados de Portugal pela língua, né? É curioso. São várias as alterações propostas: cai o hífen dobrando-se o ' $r$ ' ou o ' $s$ ' em palavras como ultra-som e contra-regra, por exemplo. Cai o trema sobre palavras como lingüiça, sai o acento circunflexo de certos verbos, também o chamado chapeuzinho de palavras como vôo, enjôo, cai o acento agudo de idéia, assembléia. Também as paroxítonas compostas como ' $\mathrm{i}$ ' e ' $\mathrm{u}$ ' em feiúra e, por fim, o alfabeto recepciona oficialmente as letras $\mathrm{k}, \mathrm{w}$ e y que estavam de intrometidas na língua. O jornalista Ruy Castro diz hoje, na Folha, que afinal poderá escrever seu nome com y sem contestação. É difícil, não é? Mas isso vai estar tudo na internet. Se errar o sistema corrige. A internet, hoje, mais que as bibliotecas, é o grande templo na cultura universal.

(Apresentador/Carlos Nascimento) É, você também vai poder escrever seu nome com y, agora, oficialmente...

(Apresentadora/Cynthia Benini) Com y... eu lembro que quando eu era pequena era difícil. A professora não..., se recusava a botar o y.

(Apresentador/Carlos Nascimento) Resolveu. Agora, por exemplo, se vai acabar o trema a gente vai falar lingüiça ou linguiça? (risos).

(Apresentadora/Cynthia Benini) risos.... Bom, as pessoas já falam muito errado, acho que vão 


\section{continuar então, pelo jeito ${ }^{[20]}$.}

O que foi colocado em jogo, nos recortes que fizemos a partir de alguns exemplares de textos em circulação na mídia (notadamente pelos destaques), não aponta para uma política de línguas, mas para uma política de mercado que tampouco discute questões linguísticas, quando muito de dicionarização à revelia da prática histórica, enquanto estatutária. Traz à tona o embate que separa aquele que tem direito a instituir daquele que precisa adquirir direito a, como destaca Zandwais (2008), "se a influência do povo é decisiva, este povo, por outro lado, é desigual, porquanto sectariza-se, entre aqueles cujos falares são social e culturalmente legitimados e aqueles cujos falares precisam adquirir direito de cidade para que sejam inscritos no vernáculo".

Desse modo, o embate se dá entre culto e não-culto, entre certo e errado, disjunções que, ao invés de irem ao encontro do desejo de 'unificação' (não compartilhado aqui), reforçam a manutenção de um ideal de língua literária, patrimônio da 'humanidade', relíquia a ser contemplada em museus de culto ao belo e inacessível ao homem comum.

Na esteira disso, os exemplos acima presentificam uma memória (cf. Zandwais, 2008) de interdição de línguas em nosso País, de interdição de falas de estrangeiros e de indígenas, que seriam então os verdadeiros párias e detratores do belo idioma, perante uma sociedade letrada, isso tudo pela via institucional político-jurídica ${ }^{[21]}$, em um País onde vemos o ideal de língua nacional única recobrir uma infinidade de línguas e falares.

O caráter 'político' que vimos sublinhando fundamenta-se em uma perspectiva materialista de compreensão dos discursos que constituem o real, significado em linguagem (Rancière, Orlandi, Guimarães) ${ }^{[22]}$. Desse modo, entendemos o político não vinculado a priori a políticas linguísticas, por exemplo, mas esse como o caráter basilar na constituição de uma formação social, o que implica pensar no modo de estruturação histórica das relações sociais, assentadas na diferença, na divisão entre aqueles que podem ou não (se) dizer, aqueles que têm direito (ou não) à palavra, que são (ou não) significados, caráter este que, não raro, políticas vêm a diluir ao positivar, afirmar pretensas igualdades. Vale dizer que o 'político' não se 'com-forma' à política, é um processo em constante devir porque constitutivo do real.

Por outro lado, é importante salientar a complexidade desse cenário. Müller (2006, 2002, 2001), em vários de seus trabalhos, tem destacado a relevância de políticas que tragam em seu bojo preocupações oriundas de discussões no seio das comunidades linguísticas e fruto de pesquisas, fomentando o debate em torno de políticas de registro, que efetivem, além do reconhecimento de línguas praticadas no País, sua circulação e manutenção. O autor considera a política de registro como um passo legitimador importante no sentido de garantir o direito a elas, sua manutenção, a fim de que as diferentes línguas sejam, além de descritas, legitimadas e, especialmente, a cultura e singularidades de comunidades como as indígenas, por exemplo, sejam firmadas como patrimônio cultural mediante a efetiva participação das comunidades, fortalecendo sua representatividade no quadro multilíngue nacional.

Para o referido autor, o interesse fulcral não deve ser o de descrição de línguas que estariam sob o risco do desaparecimento, o que viria a instituir saberes de colecionador, circunscritos aos muros das universidades, mas "o fundamental são as pessoas que falam a língua, os projetos políticos que têm e a nossa intervenção no sentido de ajudar nos aspectos políticos relacionados com o que tais línguas significam para essa sociedade” (Müller, 2001).

Dessa forma, uma política de registro, na concepção de Müller e Morello (2006), contempla: a promoção do direito às línguas; a instalação de políticas de registro e circulação 
de línguas; a elaboração de equipamentos - instrumentos e dispositivos articulados às políticas linguísticas. Nessa direção, tais políticas vêm ao encontro da diversidade de línguas, pondo em questão o ideário da Língua Portuguesa como a única no/do Estado brasileiro.

Sobretudo, o que vimos ressaltando caracteriza o político na língua como efeito da divisão que emerge do funcionamento de um social pulverizado e estratificado e que incontornavelmente redunda em produções linguageiras como significação desse mundo. Diríamos ainda que o político é um efeito da ideologia, esta compreendida enquanto direção de sentidos que aponta mesmo para as filiações destes e portanto, circunscreve o caminho histórico que leva ao sentido/interpretação, não a 'uma', e não também a 'qualquer uma', porque o dizer se historiciza mediante um trajeto descontínuo, mas materializado em práticas de sentido.

\section{Conclusão}

O que há de novo no velho AO e a reiteração de preconceitos linguísticos

Para nós, o caráter novo apenas se afigura na instância da circulação em massa, pois a constituição desse dizer é já, em tempos de voláteis relações, de espaço-tempo fluidos, tardia. O debate acerca da língua embarca nessa fluidez, não se sabe de onde vem, mas sabe-se que a nova demanda que se apresenta a professores de Língua Portuguesa é a de ensinar a seus alunos as novas regras, sob pena de ficarem, professores e alunos, desatualizados.

Diante dos recortes que exemplificaram nossa reflexão, pensamos ser, no mínimo, problemática uma prática a encampar tal urgência e direcionada a crianças e adolescentes, em processo de aprendizagem, e que ora se veem bombardeados por uma lista infinda de regras a serem memorizadas, na contramão de um processo em que nem mesmo especialistas ou cientistas da linguagem têm um posicionamento consensual, no tocante à grafia 'mais correta' de determinadas palavras. Ademais, mesmo antes do NAO, esses sujeitos já se encontram imersos em um processo de aprendizagem de um saber escolar que lhes requer memorizar regras acerca de grafia, às quais as novas se somariam, modificando o que já poderia estar de algum modo assimilado e que deve, a partir de então, ser reconfigurado, no processo de escritura.

Na esteira da 'novidade', no cenário da escritura digital e online, proliferam corretores ortográficos e dicionários que são disponibilizados por softwares processadores de texto. Por outro lado, o mais utilizado dentre eles, o Word, distribuído pela Microsoft, ainda não dispõe de ferramentas adaptadas ao NAO, mas já há sites que oferecem serviços que visam a dirimir as dúvidas relativas às mudanças, bastando, para tanto, que você digite a palavra ${ }^{[23]}$.

Os dados que aqui recortamos encontram aporte na noção de historicidade desenvolvida por Orlandi em vários de seus textos, isto é, em uma memória lacunar de dizeres, não sujeita ao tempo cronológico como tal, mas ao funcionamento deste, portanto passível de falhas e que, desse modo contraditório, temporaliza (cf. Guimarães, 2005) os dados, tornando-os fatos de discurso, ao caracterizá-los como acontecimentos: encontro de uma memória com uma atualidade (cf. Pêcheux, 1983). Jogo que põe em cena as relações entre constituição/formulação/circulação, que não busca a origem dos dizeres, mas suas filiações históricas, que direcionam e dividem os sentidos, estabelecendo lugares simbólicos para os sujeitos, para as línguas nas sociedades. O imbricamento de tais relações é profícuo para se pensar a historicidade, para se observar os movimentos político-ideológicos que constituem todo dizer, o que nos leva a compreender a formulação NAO como opaca e equívoca, enquanto nela ressoa como constitutivo um passado de colonização. 
Para mais, esse novo velho reforça o louvor a uma língua literária, a uma língua erudita regida por políticas de mercado e não por uma ética que abarque o caráter multilíngue brasileiro e conceba a língua como herança cultural que tem uma história própria, vinculada às identidades, sempre em processo, de um povo. Porque 'a gente' é uma nação que 'chama ela', chama a Língua Portuguesa de 'brasileiro' ('Eu falo brasileiro'). Enquanto isso segue o debate sobre 'uma' língua nacional encabeçado especialmente por não-linguistas, por aqueles bons sujeitos, sempre dispostos a ajudar, isto é, a opinar sobre quaisquer assuntos, afinal, de português todo mundo entende(?), menos o povo.

\section{Referências}

COMUNIDADE DOS PAÍSES DE LÍNGUA PORTUGUESA - CPLP. Acordo Ortográfico da Língua Portuguesa. Disponibilidade em: http://www.cplp.org/Admin/Public/DWSDownload.aspx? File $=\% 2$ fFiles \%2fFiler\%2fcplp\%2fAcordos\%2fmaisAcordos\%2fAcordoOrtogrLinguaPortug.pdf.

COMUNIDADE DOS PAÍSES DE LÍNGUA PORTUGUESA - CPLP. Perguntas frequentes sobre o Acordo Ortográfico. Disponibilidade em: http://www.cplp.org/Default.aspx? $\mathrm{ID}=246 \& \mathrm{PID}=287 \& \mathrm{M}=\mathrm{NewsV} 2 \& \mathrm{PID}=287 \&$ Action $=1 \& \mathrm{News} I d=114$.

CORTEN, André. Discurso e representação do político. In: INDURSKY, Freda; FERREIRA, Maria Cristina (Orgs.). Ensaios: Múltiplos territórios da Análise do Discurso. Porto Alegre, RS: Sagra Luzzatto, 1999.

GUIMARÃES, Eduardo. Política de línguas na lingüística brasileira. In: ORLANDI, Eni P.

(Org.). Política Lingüística no Brasil. Campinas, SP: Pontes, 2007. p. 63-82.

Semântica do acontecimento. Um estudo enunciativo da designação. 2. ed. Campinas, SP: Pontes, 2005.

. Brasil: país multilíngüe (Apresentação). Ciência e Cultura, São Paulo, v. 57, n. 2, June 2005a . Disponível em: <http://cienciaecultura.bvs.br/scielo.php? script=sci_arttext\&pid=S0009-67252005000200014\&lng=en\&nrm=iso >. Acesso em: Nov. 2007.

. Enciclopédia das línguas do Brasil. Política de Línguas. Disponível em htttp://geocities.com/gt_ad/Eduardo.doc. Acesso em 12 Abr. 2006.

. Enunciação e política de línguas no Brasil. Letras, n. 27, Jul./Dez. 2003. Santa Maria: PPGL, 2003. Disponibilidade em http://w3.ufsm.br/revistaletras/artigos_r27/revista27 4.pdf.

LOIOLA, Rita. O futuro do português. Super Interessante. Ed. 259, dez. 2008. São Paulo, SP: Ed. Abril, 2008.

MACHADO, Josué. Hora de remarcar os dicionários. Revista Língua Portuguesa. N. 35, setembro de 2008. São Paulo, SP: Ed. Segmento, 2008. p. 28-32.

OLIVEIRA, Gilvan Müller de; Morello, Rosângela. Livro de Registro das Línguas: uma Política Patrimonial para as Línguas Brasileiras. III Seminário Interamericano sobre a gestão das línguas:

As políticas lingüísticas das Américas em um mundo multipolar - Anais

2006. Disponível em: <http://dtil.unilat.org/tercer_seminario/actas/morello_muller-oliveira_pt.htm>. Acesso em jun. 2009.

OLIVEIRA, Gilvan Müller de. Brasileiro fala português: monolingüismo e preconceito lingüístico. In: SILVA, Fábio Lopes da; MOURA, Heronides M. de Melo (Orgs.). O direito à fala. A questão do preconceito lingüístico. 2. ed. rev. Florianópolis, Insular, 2002.

$\begin{array}{ccc} & \text {. Língua entre os dentes. Jornal da Unicamp. Caderno Temático, n. 165, ago., 2001. São } \\ \text { Paulo: } & \text { Campinas, } & \text { Disponível }\end{array}$ < http://www.unicamp.br/unicamp/unicamp_hoje/ju/ago2001/unihoje tema165pag04.html> Acesso em jun. 2009. 
ORLANDI, Eni P. Há palavras que mudam de sentido, outras... demoram mais (Apresentação). In: ORLANDI, Eni P. Política Lingüística no Brasil. Campinas, SP: Pontes, 2007. p. 7-10.

2005.

Discurso e texto. Formulação e circulação dos sentidos. 2. ed. Campinas, SP: Pontes,

PÊCHEUX, Michel. O Discurso. Estrutura ou acontecimento. Trad. de Eni P. Orlandi. 3. ed. Campinas, SP: Pontes, 1990 [1983].

PORTAL DA LÍNGUA PORTUGUESA. História da ortografia do português. Disponibilidade em: http://www.portaldalinguaportuguesa.org/?action=acordo-historia. Acesso em 13/12/2008.

RANCIÈRE, Jacques. Aux bords du politique. Paris: Gallimard, 1998.

O desentendimento. Política e Filosofia. Trad. Ângela Leite Lopes. São Paulo: Ed 34, 1996.

REPÚBLICA FEDERATIVA DO BRASIL. DIÁRIO OFICIAL DA UNIÃO - DOU, Seção 3, Avisos, n. 46, 07/03/2008. Disponibilidade em https://www.in.gov.br/imprensa/visualiza/index.jsp? jornal=3\&pagina $=31 \&$ data $=07 / 03 / 2008$.

ZANDWAIS, Ana. O discurso superestrutural sobre a "proteção" da língua no Brasil: ressonâncias interdiscursivas. IV Encontro do Gel e II Colóquio do Grupo de Estudos M. Pêcheux. Laboratório Corpus/PPGL/UFSM, Santa Maria. 25 jun. 2008. Conferência.

[1]

Ver

em:

$<$ http://www.cplp.org/Admin/Public/DWSDownload.aspx?

File=\%2fFiles\%2fFiler\%2fcplp\%2fAcordos\%2fmaisAcordos\%2fAcordoOrtogrLinguaPortug.pdf $>$.

[2] Ver em: < http://www.cplp.org/Acordo Ortográfico.aspx?ID=176>.

[3] CPLP - Comunidade dos Países de Língua Portuguesa, em: <http://www.cplp.org/Perguntas_frequentes_(2).aspx? $\mathrm{ID}=245>$.

[4] Decreto no - 6.583, de 29 de setembro de 2008, publicado no DOU de 30 de setembro de 2008. Disponível em: $<$ http://portal.mec.gov.br/arquivos/pdf/decreto6583_acordoortografico.pdf>.

[5] Quadro elaborado a partir de dados veiculados nos sites da web da Comunidade dos Países de Língua Portuguesa - CPLP (http://www.cplp.org), do Instituto Internacional da Língua Portuguesa - IILP <http://www.iilp-cplp.cv/> e da Wikipédia (http://pt.wikipedia.org). Acessos em dez., 2008.

[6]

Disponível em:

$<$ http://www.cplp.org/Admin/Public/DWSDownload.aspx? File=\%2fFiles\%2fFiler\%2fcplp\%2fAcordos\%2fmaisAcordos\%2fProtoModificAcOrtLPort.pdf $>$.

[7] Angola, Brasil, Cabo Verde, Guiné-Bissau, Moçambique, Portugal, São Tomé e Príncipe e Timor-Leste. [8]

Disponível

em:

$<$ http://www.cplp.org/Admin/Public/DWSDownload.aspx? File $=\% 2$ fFiles\%2fFiler\%2fcplp\%2fAcordos\%2fACORDO DO SEGUNDO PROTOCOLO MODIFICATIVO AO ACORDO.pdf $>$ [9]

Ver em: < http://www.cplp.org/Acordo Ortográfico.aspx?ID=176> (Acesso em 11.12.2008). A grafia que se apresenta no trecho da citação à qual se refere esta nota está em o que convencionalmente se chama 'Português de Portugal' ou mesmo 'Português Europeu', vale dizer que a CPLP tem sede na República Portuguesa.

[10]

Cf. Ministério da Educação em <http://portal.mec.gov.br/index.php?option=com content\&task=view\&id=11328>. Acesso em jun. 2009. Com a medida, a língua portuguesa será alterada em 0,8\% dos vocábulos no Brasil e 1,3\% em Portugal.

[11] Ver em: <http://www.portaldalinguaportuguesa.org/?action=acordo\&version=1943>. Negritos nossos.

[12]

Assinado pelo então presidente António Óscar de Fragoso Carmona, seguido de António de Oliveira Salazar, José Caeiro da Mata, alguns dos integrantes dos governos ditatoriais de Portugal. Negritos nossos.

[13] Negritos nossos.

[14] Daniel Silva Balaban.

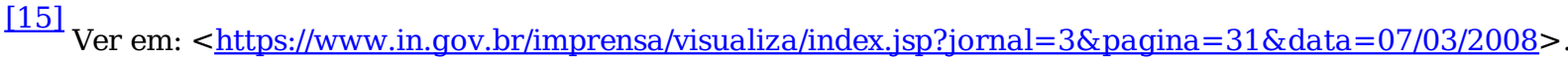

[16] Ver em: < http://veja.abril.com.br/120907/p_088.shtml>. Negritos nossos.

[17]

Guimarães (2006) traz um exemplo relevante para se pensar a questão colonização/descolonização linguística partindo do princípio de que o conjunto de línguas existentes no Brasil não é compreendido por línguas que mantenham com o Português o que a linguística comparada chama de 'relações de parentesco'.

[18] Negritos nossos.

$[19]$

Valemo-nos do exemplo analisado pela colega Caciane Souza de Medeiros (Disponível em: http://br.youtube.com/watch? 
v=9b9E35ZopGg), em seu texto $O$ que comunica e o que não comunica: a reiteração do preconceito lingüístico na mídia, publicado em Fragmentum 19. A Gramática no Tempo Presente. Santa Maria, RS: PPGL, UFSM, Laboratório Corpus, 2008.

[20] Negritos/destaques nossos.

[21] Zandwais cita como exemplo a lei 1545, de 1939, que no regime Vargas impedia o uso de qualquer língua que não fosse a Portuguesa no Brasil, assim como, antes ainda, em 1907, a Lei Adolpho Gordo que visava a expulsar do país qualquer estrangeiro entendido como uma ameaça à soberania (militantes socialistas, líderes sindicais, portadores de moléstias...).

[22]

Desenvolvemos uma reflexão no tocante ao conceito de político em: VARGAS, Rejane Arce. Dizeres ao vento??? Questionamentos sobre a questão da filiação dos sentidos. Letras (UFSM), n. 37, p. 185-200, 2009.

[23]

O site http://www.ortografa.com.br/ prevê a digitação de vocábulos e sua verificação segundo o NAO e http://www.ortografa.com.br/ e Volp e estaria em atualização 'constante'. 